\title{
Analysis of Safety Risk in University Laboratory Based on Analysis of Energy Source
}

\author{
Luo Jingjing \\ Wuhan University of Science and Technology \\ School of Resource and Environmental Engineering \\ Wuhan, China \\ 1830946041@qq.com
}

\author{
Ye Yicheng* \\ Wuhan University of Science and Technology \\ School of Resource and Environmental Engineering \\ Wuhan, China \\ yeyicheng@wust.edu.cn
}

\begin{abstract}
Determining the basic elements of laboratory safety management is one of the foundations of the safety management of university laboratory system. University laboratory is a place with small space and dense energy distribution and is not suitable for traditional industrial risk analysis. Through analyzing the disaster caused by energy in university laboratory, it was obtained that the occurrence of laboratory safety accidents was mainly due to lack of knowledge and energy control in laboratory, and so the Energy Source Risk Analysis method suitable for university laboratories was established. Through determining the energy sources and analyzing the causes leading to the loss of control of various energies in the laboratory, this paper clarifies risks faced personnel in university laboratory. Aming to control risks, this paper proposes detailed energy control measures based on analysis results. With a research-based laboratory as representative, object analysis, energy unit identification, energy source identification, risk analysis, energy analysis, energy source identification, and energy analysis were carried out and the safety risk of the energy source of the university laboratory was analyzed, which has certain guiding significance to strengthen the safety management of the laboratory based on the analysis results.
\end{abstract}

Keywords-University laboratory; Energy Source Analysis; Risk analysis; Safety management

\section{INTRODUCTION}

Laboratories are an essential place for universities to cultivate students' practical ability, creative ability and comprehensive quality. With the full implementation of the national "13th Five-Year Plan", the main development direction of the university is intensifying practical teaching and cultivating innovative talents. The construction of research laboratories in universities has not only greatly increased in quantity, but also reflected higher requirements in quality construction. University research laboratories not only undertake the scientific research and innovation tasks of the discipline, but also shoulder the task of training talents for master and doctoral students. A comprehensive university based on science and engineering, whose disciplines involves science, engineering, literature, management and medicine, its laboratories often need to use various pharmaceutical reagents, equipment and environmental facilities because of the wide range of specialties and the variety of test items. University laboratories are at the forefront of the development of science and technology. Due to the use of new materials and new technologies, as well as the characteristics of a wide range of specialties, types of experimental projects, and high mobility of personnel, the laboratory safety situation becomes more complicated. Safety management is more difficult to the laboratory. In recent years, frequent accidents and their serious consequences contradicts the practical necessity of strengthening safety management in university laboratories.

It is necessary to find out the basic elements of the safety management in the laboratory for the systematic safety management of the university laboratories. Risk analysis is to identify and analyze the risk factors existing in the system by using the principles and methods of safety system engineering, aiming to prevent accidents and achieve system safety by proposing control measures. In university laboratories, the experimental objectives of the experimenters are different because of different professional topics. The levels of laboratory safety knowledge and operating skills are equipped differently by people. Therefore, the risks in laboratories are special and unpredictable. These uncertain risks threaten the personal safety and property safety of teachers and students directly. In order to strengthen the safety management of university laboratories, it is necessary to analyze the risks in laboratories, clarify the risks exposing to laboratory personnels in laboratories, and identify the laboratory risk factors.

\section{CURRENT STATUS OF LABORATORY RISK ANALYSIS}

At present, there are a wide variety of risk analysis technologies related to industrial production at home and abroad. The dangers that appear in industrial production appear in universities laboratory too, but the risk factors that arise in the university laboratories are inherent. For example, students have not been systematically trained, various dangerous chemicals are stored in research laboratories, and the experimental process is accompanied by the generation of various energy sources such as chemical energy and mechanical energy. There are many risks in universities laboratory. Therefore, the method of industrial production risk analysis cannot be completely applied in university laboratories. Many foreign literatures devoted to solving the risks in the academic research environment have focused on risk management. Langerman applied MOC (Management 
of Change) to laboratories and made change management as part of the occupational health and safety administrative regulations [1]. Norazahar used Lab-ARBAIS (Labor Risk Behavior and Improvement System) to monitor and control the risk behavior of students in the laboratory, aiming to study the trajectory of accidents, warn students by collecting students' risky behaviors and make public announcements [2].

Researches on risk analysis methods that specially for university laboratories have started late in China and the research results have not been systematically perfected. The existing methods of laboratory safety risk analysis are mainly to analyze risk factors in the laboratory management. Tao Xingming and Zhang Xiaohong analyzed and troubles hooted the hidden dangers in the laboratory through the types of laboratory accidents [3-4]. Lu Guibin proposed six types of laboratory safety hazards, including failure to implement safety production laws and regulations, and failure to implement safety production laws and regulations by analyzing the safety features of laboratories [5]. Kang Jianxin established safety checklists for chemical laboratories in universities to identify risk factors leading to laboratory risks, then performed risk assessments and determined risk levels [6].

The management measures such as strengthening safety education, enhancing the safety awareness of teachers and students, and increasing safety investment are not practical. The safety management list is difficult to implement in daily management. Therefore, the method of risk analysis that suitable for university laboratories should be found.

\section{ENERGY SOURCE RISK ANALYSIS IN UNIVERSITY LABORATORIES}

\section{A. Energy Disasters Analysis in University Laboratories}

Many experts at home and abroad have studied the energy disaster. Nancy Leveson studied the cause of the accident from the point of energy and proposed a new type of accident model for engineering safety system [7]. Huang Lang analyzed the system energy flow direction and built a conceptual model of the accident cause based on the energy flow system, and extracted disaster reduction measures [8]. The studies of the accidents' causes from the perspective of energy have been applied in risk identification of petrochemical, coal mines, port terminals, smelting and other industries.

Based on the energy transfer theory, people use various forms of energy in order to achieve experimental goals in the laboratory. Instruments and equipment are driven by energy. Chemical reactions between chemical reagents can produce chemical energy. The operation of the instrument converts the electrical energy into mechanical energy. From point of the energy, it is a place to store energy for laboratory. The laboratory is a source of danger. Any kind of loss control of energy in the laboratory or lack of energy control may lead to accidents. In recent years, many safety accidents occur in university laboratories are related to the loss of energy control.
In recent years, safety accidents occur frequently in the university laboratories. For example, explosion accidents at Sichuan University and Tsinghua University caused serious accident consequences. By analyzing the characteristics of the accidents, it is known that these accidents occurred during the process of energy generation, conversion and working. In order to achieve experimental goals in the experimental process, measures must be taken to control the energy, so that energy can flow in accordance with people's prescribed energy circulation channels. The occurrence of these accidents is due to the loss of control of energy, which can result in excessive energy and lead to accidental release or escape of energy in violation of human desires.

Analyzing laboratory accidents from the point of energy, there are two main reasons that accidents occur in the laboratory. First, the experimenters have insufficient understanding of the energy existing in the laboratory, which can result in personal protection insufficiently in the experiment and observe the operating rules not strictly. Storage and treatment measures for various dangerous chemicals and wastes are not standardized, and improper handling after operation error. Second, laboratory managers haven' $t$ controlled the energy within the laboratory premises, resulting in the failure to install automatic parts and monitor alarm devices, instrumentation and equipment are flawed. There are hidden circuit hazards and ventilation hazards in the laboratory, and necessary emergency plans are lacked. Therefore, it is necessary to further analyze the risk factors that cause energy excess release by identifying the energy sources existing in university labs, and then propose energy control measures based on the identification analysis results. It is an effective means to control laboratory risks and reduce accidents to strengthen laboratory personnel and safety managers' knowledge and control the energy in the laboratory.

\section{B. Energy Source Analysis}

The Energy Source Analysis (ESA) is a qualitative risk analysis method based on the theory of energy accidental release [9]. The process of energy source analysis is as follows.

1) Analysis target confirmation: The analysis target is a laboratory system or a single laboratory.

2) Energy unit division: According to the different function of the unit in the system, different energy units are divided. A laboratory can be divided into an instrument experiment table, a medicine storage cabinet, etc. Then the energy sources in the energy unit are analyzed one by one.

3) Energy source identification: Identifying energy entities in a particular location that can cause accidents if the shielding fails. The hazardous chemicals, electrical facilities, and mechanical equipment in the laboratory are all energy entities.

Risk analysis: Analyzing the potential risks caused by accidental release of identified energy sources and the factors that lead to the accidental release of energy sources. For example, electrical facilities in the laboratory may cause 
electrical shock, and fire hazards, dangerous chemicals may cause poisoning, fire and explosion risk.

Energy source analysis can be used to analyze risks in university laboratories, and then formulate specific and detailed laboratory energy control measures based on identification analysis results to enhance the practical operability of risk control measures. It is beneficial for laboratory personnel and laboratory safety managers to understand and control risks in laboratory. The implementation of the daily safety management in the laboratory can be more convenient and laboratory safety accidents would be reduced.

\section{THE EXAMPLES OF LABORATORY RISK ANALYSIS}

\section{A. Introduction of laboratory}

Due to the large number of scientific experiments and the complex experimental conditions in laboratories, there are many representative energy sources in the laboratories. A research-type analytical laboratory with academic characteristics is chose as representative for the energy source analysis. The functional zone and distribution map of the laboratory is shown in Fig. 1.

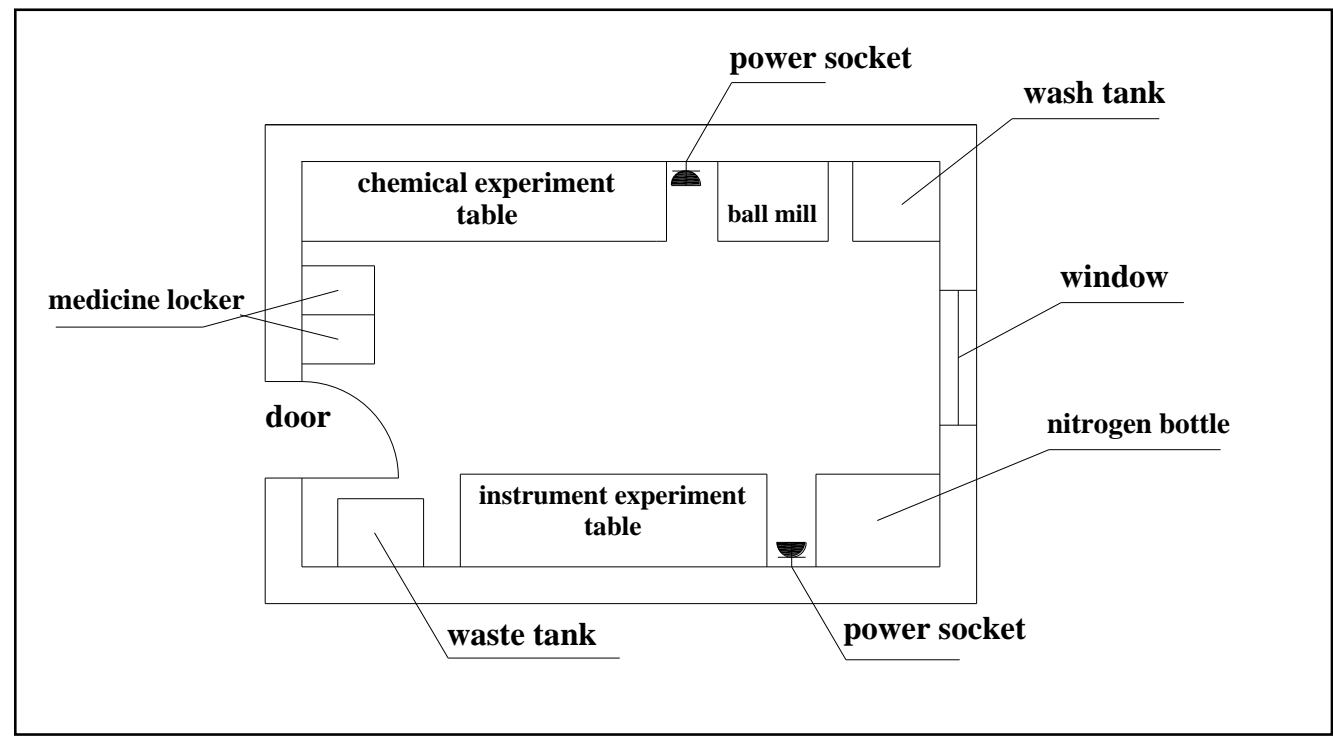

Fig. 1 Laboratory function zoning and material distribution

\section{B. Laboratory Energy Units Division}

According to different functional areas in the laboratory, the laboratory environment is divided into 8 energy units, including medicine lockers, instrument experiment table, chemical experiment table, gas bottle area, wash tank, equipment areas, power zone and waste tank. Concentrated sulphuric acid, concentrated ammonia, concentrated phosphoric acid and other chemicals are stored in the laboratory medicine lockers. Magnetic heating stirrers, thermostatic magnetic stirring water baths and other electrical equipment are placed on the instrument experiment table. Mechanical equipment includes a ball mill. There is a nitrogen cylinder in the laboratory.

\section{Laboratory Energy Unit Analysis}

Energy source analysis is performed on the divided laboratory energy units described above.

Energy can transform and work with human activities. The energy forms are different before and during the experiment. Therefore, in order to fully analyze the safety risks of the laboratory, the energy sources existing in the energy units before and during the experiment are analyzed. And then the main risks exposing to the laboratory personnel in the laboratory and the risk factors that lead to the risk are identified. The results of ESA analysis before and during the experiment are shown in TABLE and TABLE.

According to Table I and Table II, the laboratory's energy sources include chemicals, nitrogen bottles, glassware, electrical equipment, mechanical equipment and power outlets. The main risks that may occur in the laboratory are poisoning, fire, explosion, electric shock, burns and mechanical injuries. There are control measures mainly for various energy in the laboratory by analyzing the factors that lead to the loss of energy in the laboratory environment.

1) Chemical energy. Dangerous chemicals are placed in a classified manner, and the fire source is controlled and eliminated. The quality of the container should be strictly controlled. If it is found damaged, it must be replaced immediately. When cleaning glassware that contains residual hazardous chemicals, people must wear gloves and wash it carefully in case of spillage. And strict experimental procedures that involve the wearing of gas masks when handling toxic chemicals must be developed. Waste liquids 
should be sorted. Waste liquid should be emptied in time and gas absorption device should be installed.

2) Mechanical energy. When the machinery and equipment are in operation, personnel are stationed within safe distance and wear protective equipment.

3) Electrical energy. Lines and power protection facilities must be detected regularly. Wires and electrical equipment must not be randomly pulled. The quality of the electrical equipment and the installation process should be strictly controlled. Electrical equipment must be tested and ran before the experiment. All electrical equipment should equip a qualified grounding or zero-connect device. The power must be turned off when the electrical equipment is not in use. Wet sockets should be used to avoid touching wet hands.

4) Internal energy. Keep the nitrogen bottle in a cool place. Hold it gently and keep it upright. Discontinue use immediately when the leak is found and replace the rubber hose.

\section{CONCLUSION}

(1)University laboratories have different functions. There are large differences in distribution of materials and energy, constituting a complex security situation. The risks in laboratory are unpredictable. Industrial risk analysis methods

TABLE I. STATISTICAL ANALYSIS OF ESA RESULTS BEFORE THE EXPERIMENT

\begin{tabular}{|c|c|c|c|c|}
\hline Energy unit & Energy source & $\begin{array}{l}\text { Risk (possible } \\
\text { accident) }\end{array}$ & Risk factors & Propose control measures \\
\hline Medicine locker & chemicals & poisoning & $\begin{array}{l}\text { The leakage caused by package rupture lead } \\
\text { to the failure of energy shielding and the } \\
\text { formation of steam, interfering with the } \\
\text { normal energy exchange between the human } \\
\text { body and the outside world, which may } \\
\text { result in poisoning accidents. }\end{array}$ & $\begin{array}{l}\text { The quality of containers must be } \\
\text { strictly controlled. }\end{array}$ \\
\hline Cylinder area & nitrogen bottle & explosion & $\begin{array}{l}\text { The container is cracked because of high } \\
\text { temperature, impact, extrusion, etc. It may } \\
\text { result in failure of energy shielding, } \\
\text { excessive energy generation and explosion } \\
\text { hazard. }\end{array}$ & $\begin{array}{l}\text { It must be stored in a cool place, } \\
\text { hold it gently, and always keep it } \\
\text { stand upright. }\end{array}$ \\
\hline $\begin{array}{c}\text { Instrument } \\
\text { experiment table }\end{array}$ & $\begin{array}{l}\text { electrical } \\
\text { equipment }\end{array}$ & $\begin{array}{c}\text { fire } \\
\text { explosion }\end{array}$ & $\begin{array}{l}\text { Non-charged metal enclosures of mobile } \\
\text { electrical equipment may cause electric } \\
\text { shock accidents if electric energy is applied } \\
\text { to the human body and exceeds the human } \\
\text { body's capacity because of poor insulation, } \\
\text { leakage, and electrostatic induction. }\end{array}$ & $\begin{array}{l}\text { Turn off the power when the } \\
\text { instrument is unused. All electrical } \\
\text { equipment should be equipped a } \\
\text { qualified grounding or zero- } \\
\text { connection device. }\end{array}$ \\
\hline Power area & wire & fire & $\begin{array}{l}\text { The aging of the power cable and the } \\
\text { excessive power load cause the failure of } \\
\text { energy shielding, generate excessive energy, } \\
\text { it may cause fire finally. }\end{array}$ & $\begin{array}{c}\text { Lines must be regularly inspected } \\
\text { and electricity protection facilities } \\
\text { must be used. }\end{array}$ \\
\hline Waste tank & waste liquid & Poisoning & $\begin{array}{l}\text { If the waste liquid contains toxic substances, } \\
\text { certain substances can evaporate at room } \\
\text { temperature and have a strong toxic effect, } \\
\text { which interferes with the exchange of normal } \\
\text { energy between the human body and the } \\
\text { outside world, it may cause poisoning. }\end{array}$ & $\begin{array}{l}\text { Waste liquid must be emptied in } \\
\text { time and gas absorption device } \\
\text { must be installed. }\end{array}$ \\
\hline
\end{tabular}


TABLE II. STATISTICAL ANALYSIS OF ESA RESULTS IN THE EXPERIMENT

\begin{tabular}{|c|c|c|c|c|}
\hline Energy unit & Energy source & $\begin{array}{l}\text { Risk (possible } \\
\text { accident) }\end{array}$ & Risk factors & Propose control measures \\
\hline Medicine cabinet & chemicals & $\begin{array}{c}\text { fire } \\
\text { explosion }\end{array}$ & $\begin{array}{c}\text { The packaging is broken, the energy shielding } \\
\text { is ineffective, these all can cause leakage. The } \\
\text { energy is out of control if there is an ignition } \\
\text { source, it may result in fire and explosion } \\
\text { accidents. }\end{array}$ & $\begin{array}{l}\text { The sources of fire must be } \\
\text { controlled and eliminated, } \\
\text { dangerous chemicals must be } \\
\text { classified and placed. }\end{array}$ \\
\hline Gas cylinder area & nitrogen bottle & asphyxia & $\begin{array}{l}\text { The leakage of nitrogen can interfere with the } \\
\text { exchange of normal energy between the } \\
\text { human body and the outside world, it may } \\
\text { cause the hypoxic asphyxia of experimental } \\
\text { personnel. }\end{array}$ & $\begin{array}{c}\text { It must be immediately stopped and } \\
\text { the rubber hose was replaced if the } \\
\text { leakage is found. }\end{array}$ \\
\hline $\begin{array}{c}\text { Instrument } \\
\text { experiment table }\end{array}$ & $\begin{array}{l}\text { electrical } \\
\text { equipment }\end{array}$ & $\begin{array}{l}\text { burns } \\
\text { fire }\end{array}$ & $\begin{array}{l}\text { 1. Failure of energy shielding such as leakage } \\
\text { of equipment and pipelines, which may lead } \\
\text { to leakage of corrosive substances or direct } \\
\text { contact with laboratory personnel, it may } \\
\text { cause corrosion of the equipment or cause } \\
\text { burns to personnel; } \\
\text { 2. If the instrument is welded or the bolt } \\
\text { connection is partially loosened, the contact } \\
\text { resistance may increase, and the joints may } \\
\text { overheat; Excessive energy generated by the } \\
\text { electrical equipment such as poor heat } \\
\text { dissipation may cause fire. }\end{array}$ & $\begin{array}{l}\text { Electrical equipment must not be } \\
\text { disrupted. If the equipment is } \\
\text { overheated, the equipment must be } \\
\text { deactivated and inspected. }\end{array}$ \\
\hline $\begin{array}{l}\text { Chemical } \\
\text { experiment table }\end{array}$ & $\begin{array}{l}\text { Chemicals } \\
\text { glassware }\end{array}$ & $\begin{array}{l}\text { fire } \\
\text { explosion } \\
\text { poisoning } \\
\text { burns }\end{array}$ & $\begin{array}{l}\text { 1. The reaction heat of chemicals has not } \\
\text { been removed in time during the operation, } \\
\text { improper operation of distillation, contraction } \\
\text { with taboo substances, etc. May cause the } \\
\text { uncontrolled energy, which may result in fire } \\
\text { and explosion accidents. In the process of } \\
\text { operation, it may also cause poisoning; } \\
\text { 2. Inadvertent operation, rupture of the } \\
\text { container or glassware, failure of the energy } \\
\text { shielding, leakage of corrosive substances or } \\
\text { direct contraction with laboratory personnel } \\
\text { may cause burns. }\end{array}$ & $\begin{array}{c}\text { Experimental operating procedures } \\
\text { based on the hazardous substances } \\
\text { present must be formulated in the } \\
\text { laboratories; people must wear } \\
\text { respirators when handling toxic } \\
\text { chemicals. }\end{array}$ \\
\hline Wash tank & $\begin{array}{l}\text { Residual } \\
\text { chemicals }\end{array}$ & burns & $\begin{array}{l}\text { In contact with the residual chemicals directly } \\
\text { in the glassware during the cleaning process. } \\
\text { The energy acts on the human body and } \\
\text { exceeds the human body's ability to bear, it } \\
\text { may cause burns. }\end{array}$ & $\begin{array}{c}\text { People must wear gloves during } \\
\text { the experiment and the containers } \\
\text { should be washed carefully in case } \\
\text { of spillage. }\end{array}$ \\
\hline Equipment area & ball mill & $\begin{array}{l}\text { mechanical } \\
\text { injury }\end{array}$ & $\begin{array}{l}\text { When the equipment is in operation, the fast } \\
\text { moving parts, swinging parts, and meshing } \\
\text { parts of the equipment generate energy. If } \\
\text { these parts are in direct contact with the } \\
\text { human body, the energy exceeds the human } \\
\text { body's ability to bear, it may injure } \\
\text { personnel's hands, feet, hair, and body parts, } \\
\text { resulting in machinery hurt. }\end{array}$ & $\begin{array}{c}\text { People are stationed at a safe } \\
\text { distance and must wear protective } \\
\text { equipment. }\end{array}$ \\
\hline Power zone & $\begin{array}{l}\text { socket } \\
\text { wire }\end{array}$ & $\begin{array}{l}\text { electric shock } \\
\text { fire }\end{array}$ & $\begin{array}{l}\text { 1. If the wet hand touches the socket, electric } \\
\text { energy acts on the human body and exceeds } \\
\text { the human body's ability to withstand, it may } \\
\text { result in electric shock accidents; } \\
\text { 2. The current passed by the electrical circuit } \\
\text { exceeds the load may cause fire. }\end{array}$ & $\begin{array}{l}\text { Wires must not be randomly pulled, } \\
\text { the circuit must be checked } \\
\text { regularly and power protection } \\
\text { facilities must be used. }\end{array}$ \\
\hline Waste tank & waste liquid & explosion & $\begin{array}{l}\text { If a variety of waste fluids are mixed } \\
\text { together, forming an explosive mixture, the } \\
\text { loss of energy control may result in an } \\
\text { explosion accident; }\end{array}$ & $\begin{array}{l}\text { Waste liquids must be classified } \\
\text { and placed. }\end{array}$ \\
\hline
\end{tabular}


(2)Starting from the energy existing in the university laboratory environment, an energy source risk analysis method suitable for university laboratories had been established. Identifying the energy source in the laboratory and analyzing the causes of various energy loss in the laboratory, it is a means to clarify the risks exposing to personnels in university laboratories. According to the results of the risk identification and analysis, detailed laboratory energy control measures were formulated to enhance the practical operability of risk control measures, which would facilitate the understanding and control of laboratory risks by laboratory personnel and laboratory safety managers. It is convenient for daily safety management in the laboratory. Consequently, the safety management level of the laboratory can be improved.

\section{REFERENCES}

[1] Langerman, Neal, "Management of Change for Laboratories and Pilot Plants," Organic Process Research \& Development, vol.12, pp.13051306, 2008.

[2] Shariff, A. M., and N. Norazahar, "At-risk behaviour analysis and improvement study in an academic laboratory," Safety Science, vol.50, pp.29-38, 2012.

[3] Tao Xingming, Zhang Zhixue, and Yuan Yanan, "Analysis and Countermeasures of safety hidden trouble in chemical laboratory in Higher Vocational Colleges," Research on laboratory work in Colleges and Universities, pp.56-57, 2015.(In Chinese)

[4] Zhang Xiaohong, Zhou Changming, and Shen Yonglin, "Investigation and analysis of safety hidden trouble in university laboratory and safety management," Journal of Anhui Science and Technology University, vol.21, pp.56-58, 2007.(In Chinese)

[5] Lu Guibin, Jiang Huimin, "The elementary discussions on the inspection and administration of hidden troubles of safety in laboratories of colleges and university," Experiment Technology and Management, vol.25, pp.172-175, 2008.(In Chinese)

[6] Kang Jianxin, Guo Lijie, "Investigation on safety analysis method for chemical laboratories in colleges and university," Experiment Technology and Management, vol.31, pp.203-206, 2014.(In Chinese)

[7] Leveson, Nancy, "A new accident model for engineering safer systems," Safety Science, vol. 42, pp.237-270, 2004.

[8] Huang Lang, Wu Chao, and Yang Mian, "Modeling of accident causing and prevention based on energy flow system," Journal of Safety Science and Technology, vol.12, pp.55-59, 2016.(In Chinese)

[9] Chen Quan, Shi Xuan, "Application of Energy Source Analysis in Safety Risk Identification of Coal Mine," Safety in Coal Mines, vol.47, pp.240-246, 2016.(In Chinese) 